\title{
Book Review: Innovation in Developing and Transition Countries
}

\section{New Horizons in Regional Science Series}

\author{
Mohamad Buheji ${ }^{1} \&$ Dunya Ahmed ${ }^{2}$ \\ ${ }^{1,2}$ Founders - International Institute of Inspiration Economy. \\ Received: May 28, 2018 Accepted: May 30, 2018 Online Published: June 11, 2018 \\ doi:10.5539/res.v10n3p55 URL: https://doi.org/10.5539/res.v10n3p55
}

Founders - International Institute of Inspiration Economy www.inspirationeconomy.org
Book Editors: Alexandra Tsvetkova, Jana Schmutzler, Marcela Suarez, and Alessandra Faggian. 2017

\begin{abstract}
The gap between developed countries and developing countries are increasing, rather than decreasing as it was hoped and expected in the beginning of the century. This gap is clearly reflected in the Global Innovation Index 2017. Countries in transition or in emerging economies are taking long time to figure out how to deal with innovation as currency and source of differentiation. (Buheji, 2018a).

In this review, the innovation of developing countries and those in transitions is reviewed closely through the work of Tsvetkova et. al (2017). A close recommendation is set in the conclusion of this paper about future coming work that would help developed the efforts of the concerned academics, practitioners, innovation advocates and decision makers.
\end{abstract}

\section{Introduction}

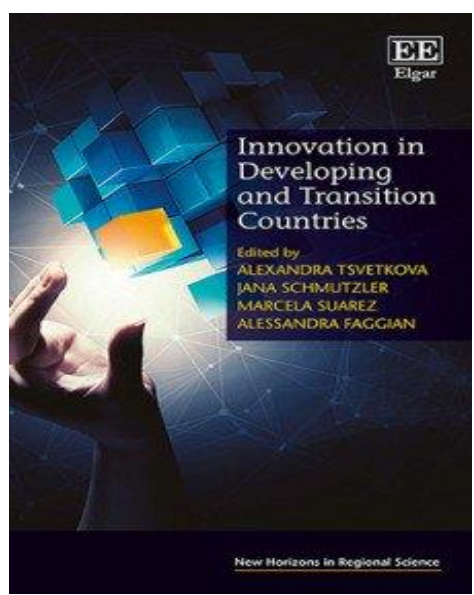

The "Innovation in Developing and Transition Countries" is an academic yet pragmatic move of the modern economists towards setting National Innovation System (NIS) in different developing and transitioning countries. NIS is a framework proposed in this book to ensure less tense transition period takes place while clearly defining the role of both government and private sector in order to build an inheritance culture of innovation. Therefore, this book is being reviewed since it addresses not only a need for an overall world socio-economic development challenges, but also shows new ways for managing such challenge and difficulties of transition toward innovation from a multidisciplinary approach and by utilizing the spirit of aspiring young scholars. It is a selective reference for innovation in different fields and from variety of prospective with a focus on innovation challenges and innovative practices in the context of developing and transition countries which the editors and the authors show through case studies of nine countries, some of which are ex-communist countries.

This work come from (Globelics) network, i.e. a book produced with specific frameworks of reference from the global network for economics of learning, innovation and competence building systems scholars. Therefore, it is logical that the book is simply divided into two part of extreme poles that the editors tries in this book to strike a balance between them. The first part tackled the current innovation policies in the countries under study, while the second part focus on current innovation challenges in these countries. Therefore, a generic National Innovation System (NIS) is suggested to help formulate practical framework initiatives and/or strategies that can be customized as per the developing countries and those in transition. 


\section{Innovation Policies and Challenges}

The first part of the book takes us through the role of public policies in developing and transforming national and sectoral innovation systems, then second part is about innovation challenges and response strategies in national and sectoral innovation systems, however with a practical consideration of firms' perspectives. The book focus on the integration of both firms and industries. The book is unique since it takes us through the reality of innovation in developing countries and in transition nations, through using mixed research methods, in an attempt to understand innovation processes. The editors highly believe that the heterogeneous and interdisciplinary team approach help to ease the establishment of the innovation and to effectively manage its challenges through smooth transforms. This is achieved through different literature review of the best practices, case studies analysis, survey based and triangulation methods of the different success stories in leading countries.

Tsvetkova et. al. (2017) work try to answer specific issues during countries transitioning towards innovation, such as answering the challenges met during the innovation process and fitness of the public policies. The editors brilliantly link the collaborative economic techniques and how it incubates and fosters innovation in the developing countries.

\section{Innovation and Learning Economies}

Innovation and learning are considered to be the theme of the book. i.e. book simply say that countries with innovative efforts and clusters won't see its capitalized efforts without effective learning. The different innovative systems in different cultures and organization community settings in different developing countries are studied; taking into consideration the bureaucratic system with certain countries. This work links to previous work of the reviewer Buheji et. al (2015). Challenges of innovative systems is being tackled in every chapter from the point of view of difficulty towards pragmatic integration that meets the needs of the industry and the government, i.e. Latin America cases specially focus on this issue.

\section{Setting the Road Map}

The Tsvetkova et. al. (2017) team shown the dilemma of setting an effective scientific agenda in developing and transitioning countries that would facilitate the technological catchup. This lead to fragmented policies and weak institutions that couldn't ensure promoting practical knowledge with clear gap between their capacity compared to the actual industrial demand. Examples of well positioned companies in the countries of focused are critically discussed. Buheji (2018b).

Role of public policies are reviewed to see the actual capability in creating a realized transformation towards the road of development that leads better innovative communities. The book focus also on the role of government actions in establishing NIS. Developing countries and those in transition have lots of opportunities that would lead to a unique innovation, Buheji and Ahmed (2018). Innovation bring Thus there are different parts and chapters that cover these issues. Challenges for innovation, role of public policies in the transformation of national innovation systems, innovation practices are all screen to see their role in successfully overcoming the different challenges of innovation, Buheji et. al. (2015). The book focus also on the role of collaboration and learning strategies by explaining different perspective on innovation practices at both macro and micro levels.

The book sees that the real difference happens when the government manage to shape the learning and build the bridges between universities and the industries. These were addressed via using different methods vary historical analysis, participatory action research, case studies, document analysis and survey-based quantitative, whom some used more than one method, by different authors each from their own perspective and historical and geographical point view; in order to effectively study innovation and adaptation strategies in developing on transition countries.

Despite the great work done in bridging the gap between innovation reality and the developing / countries in transition situation, the book fails short to address a clear generic road map for different level of development or transition that can be followed easily or that can trigger further case studies testing in the field. i.e. A clear mapping of how developing countries can be developed countries are highly suggested for future editions.

\section{Conclusion}

As reviewers of this book we believe that the authors were successful in giving the example of the role of democratic environment in upraising the innovation streams in the developing countries. The case of the Tunisian Pharmaceutical Industry is a good and contemporary example of how the overall socio-political environment enhances learning and competence building in the different sectors of innovation systems. The book show that the success factors of NIS is path dependent and shaped by history along institutional composition. Also, the editors confirm that public policies are not necessarily the main factor for better NIS. However, learning again is seen to be the prevailing factor that would differentiate the relation of innovation on the socio-economic structures. This would include exemplifying the role of developmental universities and their new social role in the economy and in the micro-economic structures. 
The work of Tsvetkova et. al. (2017) is important for developing and transitioning countries policy makers, technology transfer strategist, socio-economist, public-private relation planners and advocates, different innovation and technology industry leaders, innovation and learning focused researchers and practitioner. It is an open learning platform for those whom want to create positive transformation of their countries towards innovation and innovative cultures. The "Innovation in Developing and Transition Countries" is definitely an important reference for students and researchers interested in innovation and innovation systems around the world whom will find this book an invaluable tool for practical change in their industries and communities.

\section{References}

Buheji, M. (2018a). Book Review- Endogenous Innovation. The Economics of an Emergent System Property. Journal of Social Science Studies, 5(2), 87-88.

http://www.macrothink.org/journal/index.php/jsss/article/view/13115/10369

Buheji, M. (2018b). Book Review - Handbook of Innovation and Standards. Business and Management Studies 4(1), March, http://redfame.com/journal/index.php/bms/article/view/2977/3162

Buheji, M., \& Ahmed, D. (2018). Capturing the Innovation Opportunity Space. International Journal of Inspiration \& Resilience Economy, 2(1), 30-30. http://article.sapub.org/10.5923.j.ijire.20180201.04.html

Buheji, M., Al-Hasan, S., Thomas, B., \& Melle, D. (2015). Knowledge Management's Influence on Government Organisations' Innovativeness. Journal of Management and Organizational Studies, 2(1), 153-165. file:///C:/Users/Buhiji/Desktop/6305-20144-1-SM.pdf

\section{Copyrights}

Copyright for this article is retained by the author(s), with first publication rights granted to the journal.

This is an open-access article distributed under the terms and conditions of the Creative Commons Attribution license (http://creativecommons.org/licenses/by/4.0/). 